\title{
FORMAÇÃO CONTINUADA EM EDUCAÇÃO AMBIENTAL: USOS E POTENCIALIDADES PEDAGÓGICAS DE DADOS DE SENSORIAMENTO REMOTO
}

\author{
Continuing Training in Environmental \\ Education: Uses and pedagogical capabilities of \\ remote sensing data technology \\ Márcia Pereira Carvalho*
}

\section{Resumo}

O presente artigo apresenta os usos e potencialidades pedagógicas dos dados de sensoriamento remoto, compreendidos como saberes necessários à formação continuada em Educação Ambiental. Esta tecnologia engendra a possibilidade de uma práxis transformadora, todavia ainda se encontra interditada à maioria dos docentes, que só poderão potencializar o uso pedagógico desta mediante a formação continuada. Assim, é empreendida a análise de uma experiência de formação continuada realizada a partir do ambiente de ensino à distância TelEduc, com material desenvolvido pelo Instituto Nacional de Pesquisas Espaciais - INPE. Percebe-se que o continuum é inerente à formação de professores, tanto no que tange ao professor, quanto ao papel das instâncias formadoras. A Educação Ambiental necessita ser encarada com coragem, ousadia e senso de realidade, para que a práxis educativa possa contribuir na construção de uma sustentabilidade, tarefa que as geotecnologias em muito podem colaborar.

\footnotetext{
* Secretária Municipal de Educação de Goiânia; mestranda do curso de Pós-graduação em Sociedade, Tecnologia e Meio Ambiente pelo Centro Universitário UniEvangélica. Email: marciapereiracarvalho@ uol.com.br
} 
formação continuada e m ...

Palavras-chave: Formação continuada; Educação ambiental ; sensoriamento remoto

\section{Abstract}

The present article presents the usages and pedagogical potentialities of the data of remote sensing, understood as necessary knowledge to the continuing education in Environmental Education. This technology engenders the possibility of a transforming praxis, although it is still closed to the majority of teachers who only will be able to broaden the pedagogical use of it through a continuing education.Therefore, we proceeded an analysis of an experience of continued education carried out through distance education TelEduc, with material developed by the National Institute of Space Resarch (Inquiries)-INPE. It is perceived that the continuum is inherent to the teachers' education, both concerning to the teacher and to the role of forming instances. The Environmental Education needs to be faced with courage, boldness and sense of reality, so that the educational praxis can contribute to building a sustainable situation. The geotechnologies can contribute to this task very much.

Keywords: Continuing training - environmental education, remote sensing

\section{INTRODUÇÃO}

"a formação é um fazer permanente que se refaz constantemente na ação. Para ser, tem que se estar sendo”. Paulo Freire

Este artigo pretende apresentar os usos e potencialidades pedagógicas dos dados de sensoriamento remoto, compreendidos como saberes necessários à formação continuada de professores para a educação ambiental.

A formação de professores, desde o final dos anos de 1970, passou a colocar novas exigências para a melhoria da escola de educação básica, dando lugar a paradigmas distintos de formação profissional docente. 
Estes atentam para uma formação em que o caráter de coletividade e a consciência dos processos histórico-sociais superem a ênfase tecnicista e conteudista peculiar à formação de professores para escola básica em nosso país (FREITAS, 1999).

Nesse contexto, a formação continuada ganha importância vital ao fazer frente aos desafios das constantes mudanças científicas, tecnológicas, políticas, econômicas, sociais e culturais. Estas mudanças culminam num desafio comum a todas as áreas do conhecimento, qual seja o da própria preservação da vida, diante do que a educação ambiental coloca-se como elemento central.

De acordo com Guimarães (2004), embora a educação ambiental no Brasil esteja incorporada à escola, sendo igualmente reconhecida por seus atores, sua abordagem encontra-se fragilizada. A limitação compreensiva do professor em busca de inserir a dimensão ambiental na educação, explica as confusões conceituais comumente praticadas. Está mais do que claro a urgência de se promover um esforço formativo no intuito de renovar as ações docentes baseadas na compreensão societária da educação ambiental.

Esse cenário aponta a necessidade de convergir esforços para a formação de professores conscientes de seu papel social na promoção do entendimento dos mecanismos de inter-relação natureza-homem, em suas diversas dimensões.

O uso de dados de sensoriamento remoto é imprescindível a esta tarefa, pois permite a visualização e (re) conhecimento do território que ocupamos, aguçando a curiosidade e a percepção da perpétua mudança que se opera no espaço, transformado pelos homens e os elementos. Para Santos (2007), o conhecimento produzido e acumulado sobre o potencial das tecnologias, especialmente do sensoriamento remoto, considerado como a possibilidade de "ir ao espaço buscar soluções para os problemas da Terra", deve estar ao alcance de todos, qualificando os diversos agentes sociais para a melhoria das condições de existência.

Contudo, faz-se necessário esclarecer que para boa parte de nossos professores esse tipo de recurso encontra-se interdito na medida em que sua formação inicial não contemplou os usos e as potencialidades 
pedagógicas engendradas pelos dados de sensores remotos na educação ambiental. É o espaço da formação continuada que poderá abrir aos professores todo o sensorial e imagético suscitado pela leitura devidamente fundamentada do espaço em que vivemos.

$\mathrm{Na}$ construção desse artigo são considerados três momentos distintos, que dialogam entre si e desta forma se completam. Inicialmente, é necessário compreender conceitualmente o sensoriamento remoto, aliado às considerações pedagógicas inerentes à convergência que 0 artigo procura estabelecer entre estes dois conhecimentos. Assim, é abordado no primeiro tópico, Sensoriamento Remoto: conceito e considerações pedagógicas.

No segundo momento terá lugar a discussão acerca do sensoriamento remoto e a formação continuada de professores, como forma de potencializar a educação ambiental. O intento é promover um diálogo entre a educação ambiental e o uso de dados de sensoriamento remoto, diálogo este que será oportunizado pela formação continuada de professores.

Em seguida, o terceiro e último momento consiste na análise de programa de capacitação de professores - formação continuada - em ambiente de ensino à distância. A experiência analisada foi realizada a partir do ambiente de ensino à distância TelEduc, com material desenvolvido pelo Instituto Nacional de Pesquisas Espaciais - INPE.

Cabe ressaltar que o objetivo deste trabalho é enfatizar a pertinência do uso de dados de sensoriamento remoto na educação ambiental, como forma de socializar esta tecnologia na promoção de equidade e justiça ambiental, compromisso que deve ser renovado e cultivado constantemente, pelos caminhos da formação continuada de professores.

\section{SENSORIAMENTOREMOTO:CONCEITOECONSIDERAÇÕES PEDAGÓGICAS}

A partir da leitura de Avery e Berlin (1992), Meneses (2001) (apud FLORENZANO, 2001) e outros autores o sensoriamento remoto pode ser definido como: um conjunto de técnicas que permite obter imagens e outros dados de objetos e da superfície terrestre por instrumentos de 
captação e registro da energia refletida ou emitida pela superfície sem que haja contato físico com os objetos investigados.

Nesse sentido, o uso de dados advindos da tecnologia do sensoriamento remoto inaugura um novo tipo de relacionamento com o espaço. Outrora sua visualização se dava por meio de abstrações ritualizadas de mapas em sua maioria obsoletos que nem sempre conseguiam aguçar a percepção de seu leitor pelo planeta. O impacto das imagens do sensoriamento remoto revela uma textura rica e variada, capaz de traduzir em profundidade a fragilidade do planeta em que vivemos e a urgência de lidar com fontes reais de informação.

A captação destas imagens se dá por meio de sistemas sensores, que estão a bordo dos satélites e cumprem a função de captar e registrar a energia eletromagnética proveniente dos objetos da superfície terrestre. As imagens captadas têm diferentes resoluções divididas em quatro variáveis: resolução espacial, resolução temporal, resolução espectral e resolução radiométrica.

A resolução espacial determinará o tipo de aplicação de uma imagem, em função da escala ou detalhamento desejado da superfície, permitindo a caracterização da superfície de acordo com a quantidade de informações apropriada para aplicação com escalas diferentes.

Da mesma forma que a resolução espacial deve estar associada a uma escala espacial, na resolução temporal deve haver uma escolha coerente com a escala temporal e o dinamismo do processo monitorado. A resolução temporal se refere ao intervalo de tempo em dias, horas, que o sistema demora em obter as informações imagéticas de uma determinada região.

Como forma de viabilizar a identificação de diferentes coberturas sobre a superfície terrestre, a resolução espectral utiliza sensores com 0 objetivo de gerar diversos níveis de cinza. Quanto maior a capacidade de bandas, maior é capacidade do sensor, e mais níveis de cinza a imagem terá, permitindo a visualização de diferentes texturas.

A resolução radiométrica diz respeito à composição digital das imagens analógicas - fotografias aéreas - a partir de um conjunto de elementos denominados pixels, ordenados na forma de uma matriz 
bidimensional. Cada pixel representa uma área definida da superfície terrestre, assim a área total de todos os pixels corresponde à área total coberta pela imagem sobre a superfície.

Faz-se necessário esclarecer que o uso de dados do sensoriamento remoto na produção do saber escolar não se limita a uma mera transferência mecânica de informações para o espaço da sala de aula. Não se trata de discorrer incansavelmente acerca das resoluções das imagens de sensoriamento remoto, ou de descrever a composição dos satélites. Ao contrário, sua vigência no espaço escolar requer do professor a capacidade de operar uma transposição conceitual.

O docente deve ter clareza dos meios e fins da educação. Assim, os dados de sensoriamento remoto são meios apropriados à visualização e interpretação do espaço em que vivemos e, colaboram na consecução dos fins educacionais que culminam na revalorização da vida.

Segundo Gonçalves (2005), não se trata de proceder à simples divulgação de suas características e potencialidades, mas, sobretudo, de refletir acerca de suas especificidades e relações com a prática pedagógica, como o tratamento dos conteúdos curriculares em sua relação com a vida, visando à construção do conhecimento de professores e alunos.

Percebe-se que embora o uso de tal recurso tecnológico seja cada vez mais freqüente nos meios de comunicação visual, sua presença nas escolas ainda é pouco expressiva. A idéia de que uma tecnologia de ponta ainda é um luxo inacessível, precisa ser revista pela comunidade escolar. Só assim suas potencialidades poderão ser exploradas no estudo e compreensão do meio ambiente. Para Florenzano e Santos (1998):

As imagens de satélites proporcionam uma visão sinóptica (de conjunto) e multitemporal (de dinâmica) de extensas áreas da superfície terrestre. Elas mostram os ambientes e a sua transformação, destacam os impactos causados por fenômenos naturais e pela ação antrópica do uso e da ocupação do espaço.

Através de imagens obtidas por sensoriamento remoto, $o$ ambiente mais distante ou de difícil acesso torna-se mais acessível e menos 
abstrato. Essas imagens retratam parte, ou um hemisfério inteiro, da superfície terrestre e, portanto, permitem fazer a ligação (uma ponte) entre o pontual, ou o local, e o global. A análise local constitui referência de outros espaços, pois no local está imbutido o regional, o continental, o global e vice-versa (p. 30).

Considerar do ponto de vista pedagógico, o uso desta tecnologia, não quer dizer reduzi-la aos formalismos didáticos, mas, sobretudo, possibilitar a democratização do acesso à informação e a outras possibilidades de existência, incluindo aí não só as transformações ambientais como também as societais. Este conhecimento promove uma compreensão indivisível do espaço terrestre, recupera a dimensão de totalidade na interpretação do ambiente e alicerça a tomada de decisões.

Contudo, não há outro caminho possível para exploração dos dados de sensoriamento remoto que não seja o da formação de professores. Em primeira instância, o educador deve ter uma formação para a familiarização com todas as potencialidades engendradas pelo uso de dados provenientes desta tecnologia. E mais: deve ter a ciência de que seu papel é o de promover o encontro de seus alunos com o conhecimento, que antes de tudo é um direito de todos.

Consoante Leff (2001 , p. 255), a formação para a educação ambiental requer um "processo mais orgânico e reflexivo de organização do saber e da sociedade na construção de novas capacidades para compreender e intervir na transformação do mundo". A imagem pela sua força expressiva condensa um universo de informações que não poderiam ser visualizadas de outra forma. Estas imagens operam na construção de "novas capacidades para compreender e intervir na transformação do mundo", ao fornecerem dados acerca da realidade. Assim sendo, o professor precisa de uma formação que o municie para tal tarefa.

Os possíveis equívocos e simplificações, bem como as potencialidades e relações didáticas advindas da utilização desta tecnologia decorrem das possibilidades contempladas na formação continuada do professor. Dessa maneira, a construção das possibilidades pedagógicas deste conhecimento começa, primeiramente, na formação de professores preparados para a participação social consistente e construtiva, o que implica, entre outras 
formação continuada e m ...

coisas, no acesso ao conhecimento da função social do uso de dados de sensoriamento remoto.

\section{O SENSORIAMENTO REMOTO E A FORMAÇÃO CONTINUADA DE PROFESSORES: POTENCIALIZANDO A EDUCAÇÃO AMBIENTAL}

De acordo com Florenzano e Santos (2001), as imagens de satélites são cada vez mais freqüientes nos meios de comunicação visual, em livros e atlas, contudo até então são pouco exploradas na educação escolar. A idéia de que uma tecnologia complexa ainda é distante acaba por excluir os alunos do aprendizado que pode ser introduzido por meio deste recurso didático. No entanto, antes que o aluno fosse alijado deste processo de descoberta inerente à leitura dos dados de sensoriamento remoto, há muito o professor estava à margem deste universo.

Essa exclusão dos professores em face deste conhecimento é inaceitável, pois revoga o primado de sua função, conforme afirma Lanz (apud SENICIATO \& CAVASSAN, 2004),

A função do professor é basicamente a de trazer o mundo para dentro do contexto da aula. É esse o verdadeiro ensino. Cada dia de aula deveria ser para os alunos, uma série de vivências que Ihes despertassem a admiração, o entusiasmo diante das maravilhas do mundo, da história, da matemática, etc (p. 52).

Trazer o mundo para "dentro do contexto da aula" pode ser literalmente interpretado pelas viagens promovidas através das leituras de imagens de sensoriamento remoto. A partir de sua interpretação, sem sair do lugar, alunos e professores podem viajar pelo tempo (resolução temporal) e pelo espaço com suas muitas nuanças, cores e texturas traduzidas em informações (resolução espacial, espectral e radiométrica).

O professor, concebido como profissional que tem como matériaprima o conhecimento, é o agente capaz de receber e processar tais informações de forma significativa para o educando, capacitando-o a compreender e se posicionar frente aos problemas sócioambientais de nosso tempo. 
Santos (1998) enfatiza que o processo de socialização do sensoriamento remoto é imprescindível e, portanto, deve contar com um esforço conjunto de vários atores sociais. As instituições responsáveis pela formação de professores devem se comprometer com a socialização deste conhecimento, pois o professor, concebido como agente transformador, é quem pode promover um contato, igualmente prazeroso e crítico, com as multifinalidades do sensoriamento remoto.

Embora as informações obtidas por meio de sensoriamento remoto sirvam de base para inúmeros processos, este artigo se dedica a deslindar suas potencialidades para a educação ambiental. Compreendida como instrumento para a compreensão, conscientização e transformação frente à realidade sócioambiental, a educação ambiental se consubstancia em uma das exigências educacionais contemporâneas mais importantes.

As imagens de sensoriamento remoto retratam um hemisfério inteiro ou ainda suas partes, portanto permitem fazer a ligação entre o pontual, o local, e o global. Favorecem a leitura das implicações regionais com a qualidade de vida local e vice-versa e podem ser usadas na compreensão do processo histórico de ocupação e transformação do espaço.

Consoante Santos (2007),

as características dos produtos de sensoriamento remoto, sobretudo das imagens de satélite, tais como repetitividade de cobertura; justaposição de informações; abrangência espacial; cores e formas, apresentam importante contribuição para os estudos ambientais na escola, revelando a dinâmica do processo de construção do espaço geográfico.

A abrangência espacial e o caráter temporal das imagens de satélite, que possibilitam uma visão de conjunto da paisagem em tempos diferentes seqüenciais e simultâneos, podem auxiliar nos estudos do meio ambiente, mostrando, por exemplo, as relações entre o crescimento desordenado das cidades e a presença de rios/córregos/poluídos, favorecendo na localização de possíveis fontes poluidoras, tais como indústrias ou loteamentos irregulares, bem como subsidiar na análise do processo de uso e ocupação dos espaços, enriquecendo estudos históricos e geográficos (p. 8). 
O fato é que vivemos uma crise ambiental decorrente de processo histórico de exploração, materializada no recrudescimento dos problemas climáticos, no uso dos recursos naturais acima da capacidade de reposição, na urbanização desordenada e tantos outros sintetizados, apontando uma perspectiva apocalíptica do meio ambiente.

Todos os esforços devem ser empreendidos para alargar os conceitos de meio ambiente e educação, aprofundando também suas múltiplas e complexas relações. Da mesma forma, processos de formação profissional de professores para a prática de educação ambiental, que considerem radicalmente a relação entre conteúdo e método, as especificidades pedagógicas e o sentido da democracia escolar, precisam estar presentes nas pautas de instituições públicas e privadas (CASCINO, 2007).

A questão ambiental é uma problemática social que exige uma formação para uma racionalidade produtiva fundada no potencial ambiental de cada região para um desenvolvimento descentralizado e sustentável (Leff, 2001). Eis o principal impulso que os dados de sensoriamento remoto podem fornecer à educação ambiental. Ao retratar e possibilitar o conhecimento de forma crítica e global da própria região, os dados de sensoriamento remoto colaboram com o educador ambiental que deseja assumir com paixão e compromisso a criação de novos saberes para 0 resgate da função crítica, prospectiva e propositiva do conhecimento.

Dito de outra forma: o uso de dados de sensoriamento remoto fornece elementos para compreender e planejar intervenções no espaço. São informações que, uma vez bem trabalhadas pelo docente, permitem leituras do ambiente concebido como a integração de processos naturais e sociais de diferentes ordens de materialidade e esferas de racionalidade.

A análise de sistemas sócioambientais implica a necessidade de articular diferentes ordens de materialidade que não são apreendidas intuitivamente. Para uma abordagem investigativa do ambiente, a posse de dados concretos e a capacidade de interpretá-los é condição para estabelecer uma relação entre a realidade e o conhecimento. Seguramente, os dados de sensoriamento remoto, em suas diferentes resoluções, constituem uma poderosa ferramenta em sala de aula, sendo um material didático rico, útil e interessante para a compreensão ambiental. 
A presença deste tipo de tecnologia no espaço escolar depende igualmente da qualidade da formação de professores, e das interações que estabelecerá a partir da interlocução com seus pares. Esse saber experiencial (TARDIF, 2003), advindo da e construído na prática docente, possibilita a emergência de outras tantas possibilidades além das já enunciadas. Esse é exatamente 0 sentido do fazer docente: o professor como artesão de novas práticas e maneiras de ensinar e aprender.

Disseminar entre a comunidade docente os benefícios gerados pela tecnologia de sensoriamento remoto no conhecimento do meio ambiente, capacitando-os a buscar as diversas fontes destes dados, na promoção dos complexos processos de interações culturais no manejo ambiental, deveria ser uma constante nos cursos de formação de educadores ambientais.

Importante ressaltar que as diversas possibilidades serão despertadas a partir da frequiência a cursos de capacitação de professores. Algumas experiências nesse sentido já foram realizadas, dentre as quais se destacam os cursos para professores realizados pela Divisão de Sensoriamento Remoto (DSR) com a duração de 40h e cursos à distancia através do ambiente TelEduc em que se disponibilizavam CDs educacionais e livros acerca da temática.

\section{UMA EXPERIÊNCIA DE FORMAÇÃO CONTINUADA PARA O USO ESCOLAR DE DADOS DE SENSORIAMENTO REMOTO}

O Instituto Nacional de Pesquisas Espaciais - INPE tem desenvolvido propostas de ensino de Sensoriamento Remoto desde o ano de 1972. Inicialmente foi criado um curso de mestrado nesta área e mais recentemente, em 1998, foi implementado o doutorado. Em nível de especialização, foi desenvolvido o Curso Internacional em Sensoriamento Remoto e Sistemas de Informações Geográficas.

Além destas iniciativas no âmbito da pós-graduação, o INPE vem oferecendo cursos de curta duração dentro e fora de suas dependências. Geralmente são cursos com a duração de 40h que atendem pesquisadores, professores e técnicos de várias áreas, ligados a instituições de pesquisa, universidades e empresas que usam geotecnologias (FLORENZANO, et all, 2001). 
Outra experiência é realizada pela Divisão de Sensoriamento Remoto - DSR da Coordenação-Geral de Observação da Terra - OBT, desde 1998, durante as férias escolares do mês de julho. O curso "o Uso Escolar do Sensoriamento Remoto no Estudo do Meio Ambiente", tem a duração de 40h e destina-se a capacitação de professores do Ensino Fundamental e Médio da rede pública e particular do País. De acordo com Florenzano (2001), seu objetivo é difundir o uso de dados de sensoriamento remoto como conteúdo e recurso didático nas escolas, incentivando a elaboração de projetos pedagógicos.

Outras iniciativas de formação para o uso de sensoriamento remoto foram empreendidas e a modalidade à distância foi amplamente utilizada para esses fins. Embora a busca por uma educação à distância e de qualidade seja atualmente o maior desafio, sua vigência e expansão se justifica pelas demandas por aprendizagem, e a possibilidade de superar os limites de tempo e espaço, proporcionando grande flexibilidade. Ainda segundo Florenzano, esse tipo de formação para sensoriamento remoto à distância é coerente

à medida que crescem as aplicações das geotecnologias, aumenta a procura por cursos nessa área. Considerando a escassez de recursos e as dimensões do Brasil que dificultam $o$ acesso à capacitação e formação, é fundamental investir em educação à distância para este tipo de capacitação. A expansão crescente desta modalidade de ensino no Brasil e no mundo é favorecida pelas novas demandas educativas e pelo desenvolvimento das tecnologias da informação FLORENZANO (2001, p. 2).

Recentemente, o INPE voltou a investir na capacitação à distância usando o ambiente computacional TelEduc, desenvolvido pela UNICAMP, que permite realizar cursos pela internet. Este ambiente de aprendizagem virtual continua sendo utilizado pela OBT, com o objetivo de difundir o sensoriamento remoto e demais geotecnologias, desenvolvendo metodologias de ensino a distância. De acordo com a autora, fez-se opção em um primeiro momento pela formação de professores universitários devido ao 
seu papel multiplicador e pela infra-estrutura computacional existente nas universidades.

A primeira experiência foi realizada em maio de 2004, com duração de três semanas, a segunda com maior duração foi realizada em setembro do mesmo ano, e a terceira capacitação ocorreu em 2005, mas ainda não existem relatos disponíveis.

Os cursos contam com material didático básico: tutoriais para o uso de sistema SPRING, rotina para aquisição, leitura e georreferenciamento de imagens de satélite LANDSAT e CBERS, o livro "Imagens de satélite para estudos ambientais" e o CD educacional "Sensoriamento Remoto: Aplicações para a preservação, conservação e desenvolvimento sustentável da Amazônia".

Após a realização do primeiro curso, observou-se a necessidade de estender sua duração, sem prejudicar o aluno com o prolongamento desnecessário. Mesmo no segundo curso com duração maior, 70\% dos alunos consideraram que sua duração poderia ter sido ampliada.

Em ambas as versões, a formação de rotinas de ensino está sendo testada com a finalidade de dirimir as dificuldades observadas, tais como: a demanda para a correção de atividades, intensidade de discussões durante as sessões de bate-papo e a necessidade de orientação para evitar a dispersão das discussões.

Segundo Florenzano, embora existam ressalvas, este tipo de formação é proveitosa,

apesar das dificuldades encontradas, principalmente no segundo curso, o desempenho médio dos alunos foi muito bom, considerando a amplitude dos temas abordados, a heterogeneidade dos alunos em cursos desta natureza e a duração do curso. Entretanto, a experiência mostrou que alguns ajustes deverão ser realizados para melhorar as futuras edições como, por exemplo, redefinir o número de formadores; gerar materiais didáticos complementares em forma de tutorias ou rotinas; otimizar o uso das sessões síncronas; estimular a interação entre alunos e entre esses formadores; utilizar a ferramentas; perguntas freqüentes não 
usadas nos cursos anteriores; explorar mais as ferramentas de avaliação dentro do TelEduc e aprimorar o processo de avaliação formativa FLORENZANO (2001, p. 6).

É possível observar que a máxima de Paulo Freire inscrita no início deste artigo é confirmada pelas iniciativas de formação continuada em sensoriamento remoto. É preciso estar sendo, num refazer constante da ação. Não há receita finita para a potencialização da educação ambiental a partir do uso de quaisquer tecnologias. Há sim que se caminhar num intenso devir, em que a avaliação e o traçar de novos rumos andem interligados na busca por uma formação completa e holística.

Ao finalizar, ouso afirmar que vontade política e esforço pessoal para a profissionalização do ensino são igualmente necessários. Devem ser compreendidos como as duas faces constitutivas da mesma moeda, inseparáveis na promoção de igualdade de acesso ao conhecimento e de promoção de condições de vida digna.

A educação ambiental necessita ser encarada com coragem e ousadia, e mais do que tudo, com um enorme senso de realidade, para que a práxis educativa possa de fato contribuir na construção de uma sustentabilidade, tarefa que as geotecnologias em muito podem colaborar.

\section{REFERÊNCIAS}

CASCINO, Fábio Alberti. Conservação e Educação Ambientais: caminhos, pistas e trilhas. IN: SERRANO, Célia. Patrimônio, natureza e cultura. Campinas: Papirus, 2007.

FREITAS, Maria Helena Costa Lopes de. A reforma do ensino superior no campo da formação dos profissionais da educação básica: as políticas educacionais e o movimento dos educadores. Educação e Sociedade. n.68, Campinas: CEDES, 1999.

FLORENZANO, Tereza Gallotti et al. Formação de professores universitários em sensoriamento remoto através do ensino à distância. UNITAU, 2001 .

Textos, 2002.

Imagens de satélite para estudos ambientais. São Paulo, Oficina de 
; SANTOS, Vânia Maria Nunes. O uso do sensoriamento remoto na educação ambiental. INPE, São José dos Campos, 2000.

GONÇALVES, Marianina Impagliazzo. Uso do sensoriamento remoto na produção do conhecimento escolar como proposta para utilização das tecnologias espaciais na sala de aula. Instituto de Geociências, UNICAMP, 2005.

GUIMARÃES, Mauro. A formação de educadores ambientais. Campinas: Papirus, 2004.

LEFF, Enrique. Saber ambiental: sustentabilidade, racionalidade, complexidade, poder. Petropólis: Vozes, 2001.

SANTOS, Vânia Maria Nunes. O uso escolar de dados de sensoriamento remoto como recurso didático pedagógico. São Paulo, 2007. Disponível em: http://www.herbario. com.br/fotomicrografia07/ouso_escolar_sensoriamento.htm Acesso em: 11 de maio de 2007.

SAUSEN, T. M. Centro de Educação em Ciência e Tecnologia Espacial para América Latina e Caribe. Campus Brasil In: Anais do Simpósio Brasileiro de Sensoriamento Remoto, Belo Horizonte, 5 a 9 de abril de 2003, arquivos, 07-075 pdf, 1-7.

SENICIATO, Tatiana e CAVASSAN, Osmar. Aulas de campo em ambientes naturais e aprendizagem em ciências - um estudo com alunos do ensino fundamental. São Paulo, 2004. Ciência \& Educação, v. 10, n. 1, p. 133-147, 2004. Disponível em: http:// www2.fc.unesp.br/cienciaeeducacao. Acesso em: 20 de maio de 2006.

TARDIF, Maurice. Saberes docentes e formação profissional. Petrópolis: Vozes, 2002. 